\title{
On the transition of short cracks into long fatigue cracks in reactor pressure vessel steels
}

\author{
Rajwinder Singh ${ }^{1, *}$, Amanjot Singh ${ }^{1}$, Aman Arora ${ }^{1}$, Pawan K. Singh ${ }^{2}$ and Dhiraj K. Mahajan ${ }^{1}$ \\ ${ }^{1}$ Ropar Mechanics of Materials Laboratory, Department of Mechanical Engineering, Indian Institute of Technology Ropar, Rupnagar, \\ Punjab, India, 140001 \\ ${ }^{2}$ Reactor Safety Division, Bhabha Atomic Research Centre (BARC), Mumbai, India, 400085
}

\begin{abstract}
Short fatigue cracks, having dimension less than $1 \mathrm{~mm}$, propagate at much faster rates $(d a / d N)$ even at lower stress intensity factor range $(d a / d N)$ as compared to the threshold stress intensity factor range obtained from long fatigue crack growth studies. These short cracks originate at the sub-grain level and some of them ultimately transit into critical long cracks over time. Therefore, designing the components subjected to fatigue loading merely on the long crack growth data and neglecting the short crack growth behavior can overestimate the component's life. This aspect of short fatigue cracks become even more critical for materials used for safety critical applications such as reactor pressure vessel (RPV) steel in nuclear plants. In this work, the transition behaviour of short fatigue crack gowth into long fatigue crack is studied in SA508 Grade 3 Class I low alloy steel used in RPVs. In-situ characterization of initiation, propagation and transition of short fatigue cracks is performed using fatigue stage for Scanning Electron Microscope (SEM) in addition to digital microscopes fitted over a servo-hydraulic fatigue machine and correlated with the microtructural information obtained using electron backscatter diffraction (EBSD). SA508 steel having an upper bainitic microstructure have several microstructural interfaces such as phase and grain boundaries that play a significant role in controlling the short fatigue crack propagation. Specially designed and prepared short fatigue specimens (eletro-polished) with varying initial crack lengths of the order of tens of microns are used in this study. The transition of such short initial cracks into long cracks is then tracked to give detailed insight into the role of each phase and phase/grain boundary with an objective of establishing Kitagawa-Takahashi diagram for the given RPV steel. The behavior of the transited long cracks is then compared with the crack propagation behavior obtained using conventional CT specimens. The outcome of this research will enhance information on the integrity of the components made from RPV steel used in Indian nuclear power plants.
\end{abstract}

\section{Introduction}

A significant proportion of component's fatigue life is spent during short crack propagation [1]. Short cracks are mainly classified as mechanically short cracks (plastic zone at crack tip is less than the crack length), microstructurally short cracks (crack length is less than grain size of the material) and physically short cracks (crack length less than $1 \mathrm{~mm}$ and up to which crack closure is not eminent) [2]. The initiation of short crack propagation takes place at lower value of threshold stress intensity factor range as defined for the conventional long cracks. After initiation short cracks propagate at higher rate as compared to the long cracks for the same value of applied stress intensity factor range. Linear elastic fracture mechanics (LEFM) is not applicable in short cracks regime and the propagation behaviour of short fatigue cracks cannot be predicted by the famous ParisErdogan law [3]. Unlike long cracks, the short cracks during propagation highly interact with the inherent microstructural features of the material such as grain boundaries, phase boundaries and inclusions [4-6]. These interactions of short cracks with the microstructural features in the material will result in fluctuations in the propagation rate of the short cracks. Under the action of external loading, slip bands are formed at the crack tip due to the emission of dislocations along the active slip planes at the crack front. The short cracks tend to propagate along these slip bands by shearing due to combination of mode I and mode II loading [2]. Since the orientation of the active slip bands change with the change in the grain orientation, therefore these short fatigue cracks change their direction as they travel from one grain to the other by crossing the grain boundary [5]. The natural occurring defects in a material are of the order of short cracks, therefore it is more logical to study short fatigue crack propagations in a material.

SA508 Gr.3 Cl.I low alloy steel (LAS) is used in the manufacturing of shell of nuclear power plants [7]. The safe operation of this shell is very important for the safety of the nuclear power plant as well as the surrounding living beings and environment. As surveyed through SCOPUS database, lot of experimental investigations are being conducted by the researchers on long fatigue crack

\footnotetext{
* Corresponding author: rajwinder.singh@,iitrpr.ac.in
} 
propagation in this steel. These investigations are related to the effect of cyclic loading ratio [8], testing environment [9-12] and heat treatment [13] on the long fatigue crack propagation in this LAS. Apart from long fatigue crack propagation studies only one research paper regarding the experimental study related to the difference in short and long fatigue crack propagation rates in the LAS is available in literature [14]. Due to the abnormal propagation behaviour of short cracks and inability of the LEFM theory to model the propagation rate of short cracks, a detailed understanding regarding the interaction of short cracks with the microstructural feature in this SA508 LAS is necessary.

In the present work, the experimental investigations of mechanically short fatigue crack propagation in SA508 Gr.3 Cl.I LAS is carried out. The short fatigue crack propagation is studied at applied stress levels near to the yield strength of the material to investigate the short fatigue crack propagation rate and interaction of short crack with the microstructural features in the material. Comparison between the propagation rate of short and long cracks under cyclic loading is also done. The outcome of these investigations will enhance information on the integrity of the components made from RPV steel, which are used in Indian nuclear power plants.

\section{Experimental procedure}

\subsection{Material characterization}

SA508 Gr.3 Cl.I LAS test material in the form of pipe is received from BARC (Mumbai). The chemical composition of the material is as shown in Table 1.

Table 1. Chemical composition of SA508 Gr.3 Cl.I LAS in weight $\%$

\begin{tabular}{|c|c|c|c|c|c|}
\hline $\mathbf{C}$ & $\mathbf{S}$ & $\mathbf{P}$ & $\mathbf{M n}$ & $\mathbf{S i}$ & $\mathbf{C r}$ \\
\hline 0.19 & 0.002 & 0.018 & 1.3 & 0.23 & 0.17 \\
\hline $\mathbf{N i}$ & $\mathbf{M o}$ & $\mathbf{C u}$ & $\mathbf{A l}$ & $\mathbf{T i}$ & $\mathbf{F e}$ \\
\hline 0.7 & 0.44 & 0.13 & 0.02 & -- & 96.8 \\
\hline
\end{tabular}

For microstructural study of the material, the cube sample is polished with emery papers and alumina paste to obtain a mirror like finish. This mirror finished samples are then etched with $10 \%$ Nital solution for a period of 8 seconds to reveal the microstructure of the material under the SEM.

\subsection{Long fatigue cracks propagation test}

The compact tension (CT) specimens as shown in Figure (a) are used to study the long fatigue crack propagation in the material. Both constant load and load shredding experiments as mentioned in ASTM E647-11 are performed at a cyclic loading ratio $\left(R=P_{\min } / P_{\max }\right)$ of 0.1 and frequency of $35 \mathrm{~Hz}$ to explore the both stage I and stage II long fatigue crack propagation behaviours of the material. The crack length during fatigue loading is measured with crack opening displacement (COD) gauge. Incremental polynomial method as mentioned in ASTM E647-11 is used to compute the long crack growth rate.

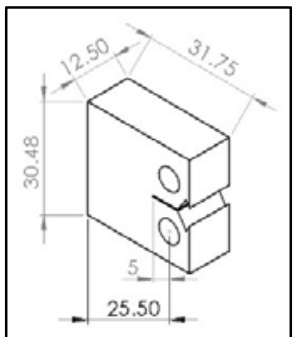

(a)

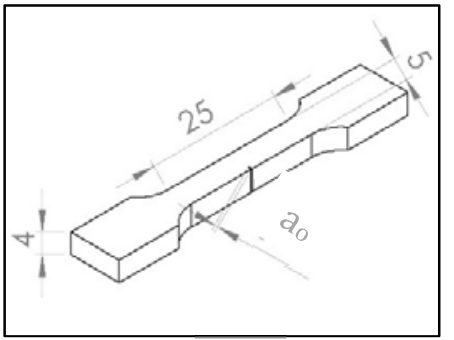

(b)
Fig. 1. (a) Compact tension (CT) specimen to study long crack propagation (b) single edge notched (SEN) specimen for short crack propagation study.

\subsection{Short fatigue crack propagation test}

The single edge notched (SEN) specimens with an initial notch size $\left(a_{0}\right)$ varying from $50 \mu \mathrm{m}$ to $100 \mu \mathrm{m}$ as shown in Figure 1(b) are used to study the short fatigue crack propagation in the material. The short fatigue crack propagation tests are carried out at applied stress range $\Delta \sigma$ of $475 \mathrm{MPa}$ at a cyclic loading ratio of 0.1 and frequency of $35 \mathrm{~Hz}$. The value of $\Delta \sigma$ is chosen such that the value of $\sigma_{\text {max }}$ during cyclic loading is near to the yield strength of the material. The yield strength and ultimate tensile strength of the material under investigation are determined experimentally by Singh et al. [15]. A new technique of short crack measurement by optical microscope is used [15]. The length of short crack during cyclic loading is measured with moving digital microscope by interrupting the cyclic loading at regular intervals. The specimen surfaces are polished with emery papers and alumina paste to obtain mirror finish, so that the short cracks propagation at the surface can be easily tracked by digital microscope. The polished and cracked specimen is then etched to reveal the inherent microstructural features of the material intercepted by the short crack path. EBSD analysis of the cracked surface is also carried out to understand the relative orientation of the grains through which the short fatigue crack passed during propagation. Secant method as mentioned in ASTM E647-11 is used to compute the short crack growth rate as.

$$
d a / d N=\left(a_{i+1}-a_{i}\right) /\left(N_{i+1}-N_{i}\right)
$$

where, $\left(a_{i+1}-a_{i}\right)$ is the increment in crack length after $\left(N_{i+1}-N_{i}\right)$ loading cycles.

\section{Results and discussion}

\subsection{Microstructure}

The inherent microstructure of SA508 Gr.3 Cl.I LAS as revealed through SEM is shown in Figure 2. The microstructure of this material is tempered upper bainitic consisting of prior austenite grain in which the carbides are distributed inside and outside the ferrite $(\alpha-\mathrm{Fe})$ laths. $\mathrm{M}_{3} \mathrm{C}$ type coarse carbides are precipitated along the $\alpha-\mathrm{Fe}$ lath boundaries whereas, $\mathrm{M}_{2} \mathrm{C}$ type fine carbides are distributed inside the $\alpha$-Fe laths. Rod shaped carbides are also distributed along the prior austenite grain boundaries 
(P $\gamma \mathrm{GBs})[13]$. The average prior austenite grain size of the material is $30 \mu \mathrm{m}$.

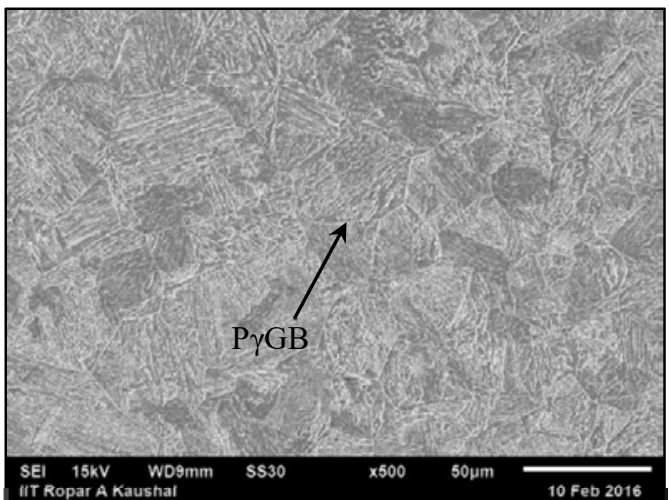

Fig. 2. Microstructure of SA508 Gr.3 Cl.I LAS as obtained through SEM

\subsection{Short and long fatigue crack propagation}

The graph of short crack propagation length with the number of cycles at applied $\Delta \sigma=475 \mathrm{MPa}$ is as shown in Figure 3(a). Three numbers of samples are tested at the same loading conditions to get the short crack data. The crack growth measurement is done up to crack length of approximately $1 \mathrm{~mm}$ to predict the short crack growth behaviour. The crack initiated after 10000, 12000 and 16000 numbers of loading cycles in sample 1, sample 2 and sample 3 respectively. The number of cycles required to initiate the short crack in all the three samples is almost the same. After the initiation of the crack, the propagation of short crack with the number of cycles is different in the three samples as per graph shown in Figure 3(a). Since the short crack propagation under cyclic loading is affected by the microstructural features in the material, therefore the difference in graph shown in Figure 3(a) for the three tested samples is because of the difference in the microstructural features and orientation of the grains being intercepted by the short crack during propagation in all the three samples. The graph of short crack propagation rate $(d a / d N)$ with the crack length $(a)$ is shown in Figure 3(b). The acceleration and deceleration in short crack propagation rate is observed due to the interaction of short cracks with the microstructural features such as grain boundaries in the material. During propagation, the interaction of short crack with the microstructural features in the material will be discussed in Section 3.3.

The variation in plastic zone size $r_{p}(\mu \mathrm{m})$ ahead of the crack tip with crack length for different applied stress levels $\Delta \sigma$ is as shown in Figure 4. The plastic zone size $r_{p}$ ahead of the crack tip under cycling loading can be evaluated as [16]

$$
r_{p}=(1 / 24 \pi)\left(\Delta K / \sigma_{Y}\right)^{2}
$$

The plastic zone size ahead of the crack tip is exceeding the value of average grain size i.e. $30 \mu \mathrm{m}$ of the material when the crack length is approximately $600 \mu \mathrm{m}$ for applied $\Delta \sigma$. Therefore, the interaction of short crack with the microstructural features is reduced after crack length of $600 \mu \mathrm{m}$ as shown in Figure 3(b).

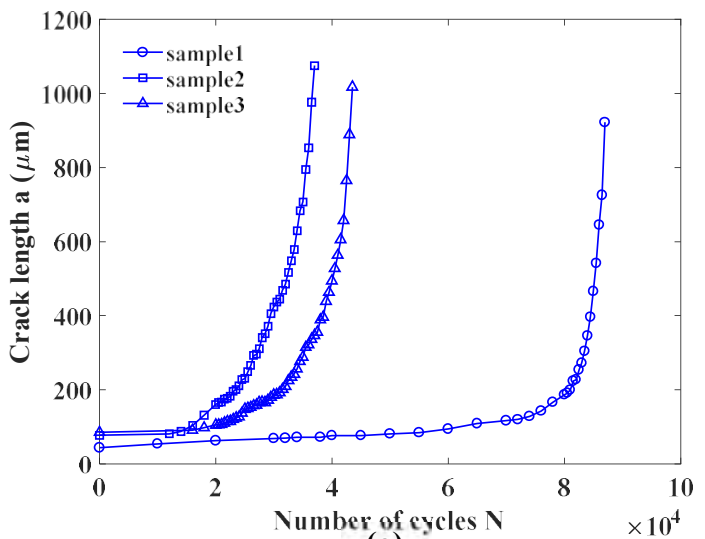

(a)

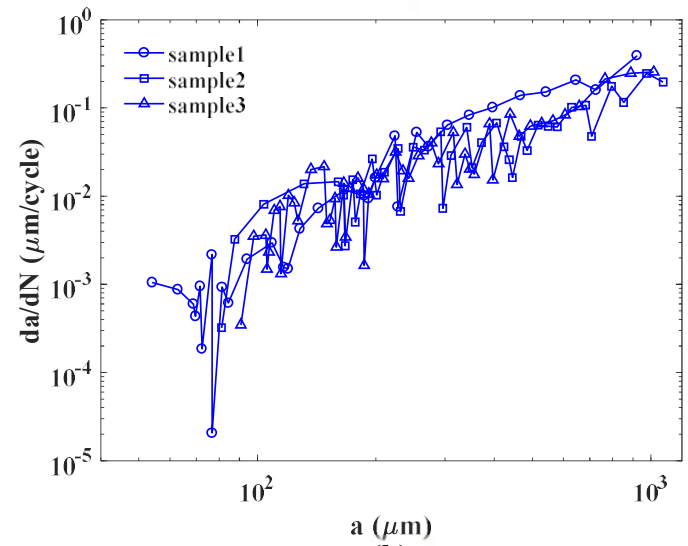

(b)

Fig. 3. (a) Short crack growth ' $a$ ' with numbers of cycles ' $N$ ' and (b) short crack growth rate ' $d a / d N$ ' with crack length ' $a$ ' at applied $\Delta \sigma=475 \mathrm{MPa}$ in SA508 Gr.3 Cl.I LAS

The concept of linear elastic fracture mechanics (LEFM) and small-scale yielding (SSY) is applicable if

$$
a / r_{p} \geq 50
$$

The value of this ratio is less than 50 in short crack regime because of small value of crack length and high value of plastic zone size. Thus, LEFM and SSY are not applicable in short crack regime.

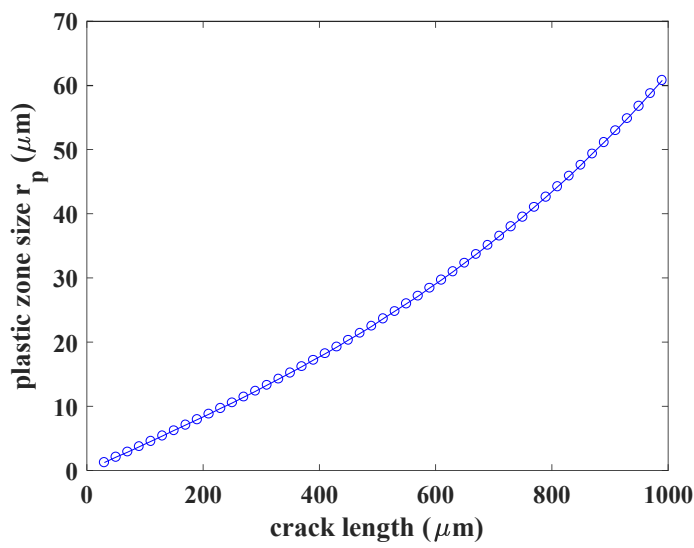

Fig. 4. Variation of plastic zone size $r_{p}$ with crack length at applied stress range $\Delta \sigma=475 \mathrm{MPa}$ in SA508 Gr.3 Cl.I LAS. 
Even though the LEFM theory is not valid in short crack regime but a graph between crack growth rate $(d a / d N)$ and stress intensity factor range $\Delta K$ is plotted for short cracks to compare the propagation rate of short and long cracks under cyclic loading as shown in Figure 5. The details regarding the long crack growth under cyclic loading and Paris law for SA508 Gr.3 Cl.I LAS can be found elsewhere [15]. The propagation rate of short cracks is higher as compared to the long cracks at higher applied $\Delta \sigma$ and thus the propagation rate of short cracks cannot be modelled by conventional Paris law as shown in Figure 5. Similar higher rate of crack propagation at higher applied stress levels in aluminium alloy is also reported in literature [17]. Therefore, the design of the pressure vessels made from this LAS merely on long crack growth data is not recommended.

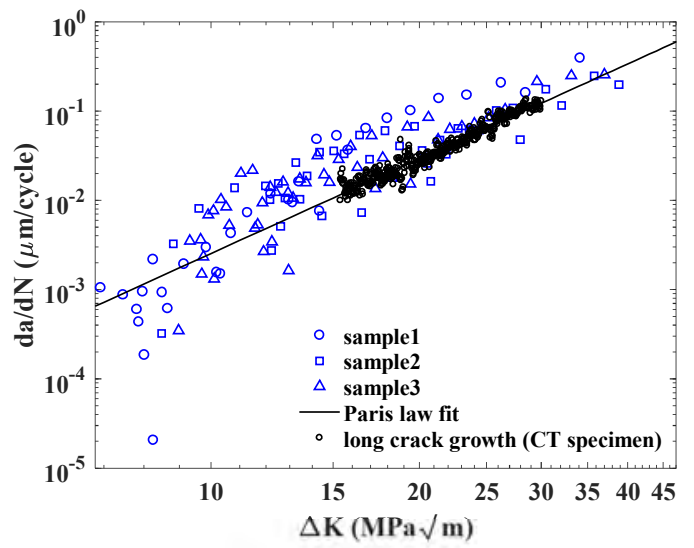

Fig. 5. Comparison of short and long crack propagation in SA508 Gr.3 Cl.I LAS under cyclic loading

\subsection{Short crack interaction with microstructure}

For studying the short crack interaction with the microstructural features in the material, the crack is made to propagate to the length of approximately $150 \mu \mathrm{m}$ under cyclic loading. In this case, the graph of the increase in short crack length with the number of applied loading cycles is shown in Figure 6(a). The corresponding graph of short crack propagation rate $(d a / d N)$ with the crack length $(a)$ is shown in Figure 6(b). The retardation in short crack propagation rate is observed at the points 1,2 and 3 as marked in the graph shown in Figure 6(b). The surface of the cracked sample is etched to observe under SEM the microstructural features in the material corresponding to the marked points 1,2 and 3. The path of short crack as observed under the SEM is shown in Figure 7(a). The zoomed view of the short crack path is shown in the inset of Figure 7(a). The points 1 to 3 corresponding to the retardation of short crack growth shown in Figure 6(b) are marked by white circles on the short crack path observed under the SEM as shown in Figures 7(b)-7(e).

Figure 7(b) shows that the retardation at point 1 is due to the PAyBs. The crack has changed its path as it crossed the PA $\gamma B$ Bs due to the change in the grain orientation. Another short crack parallel to the main crack can be seen in Figure 7(c). Away from the short crack tip another crack initiated from the triple point of the PA $\gamma \mathrm{Bs}$ as marked by point 2 in Figure 7(d). Tripe point is referred to as a point where three grain boundaries meet. These triple points act as stress raisers as reported in the literature [18]. The coarse rod type carbides distributed along the PA $\gamma$ Bs at the triple point as shown in Figure 7(d) also favoured the initiation of the crack. This crack initiated from the triple point propagated in the backward directions and met the main crack at the position marked by white square in Figure 7(c). The two short cracks then met at the triple point and then propagated together as a single short crack. The retardation in crack propagation rate at point 2 as shown in Figure 6(b) is due to the arrest of the short crack at the triple point shown in Figure 7(d) for some duration. The deceleration in crack growth rate at point 3 is due to the presence of another PA $\gamma B$ s as shown in Figure 7(e). At higher applied cyclic stress levels, the only retardation to short crack growth is offered by PA $\gamma$ Bs in SA508 Gr.3 Cl.I LAS.

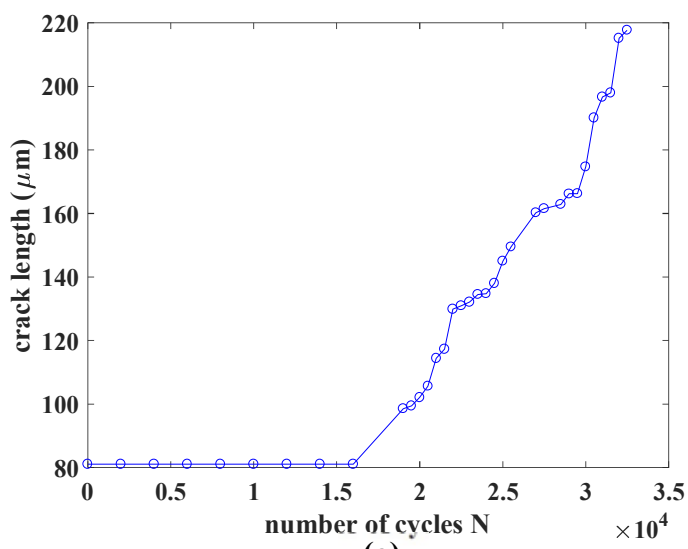

(a)

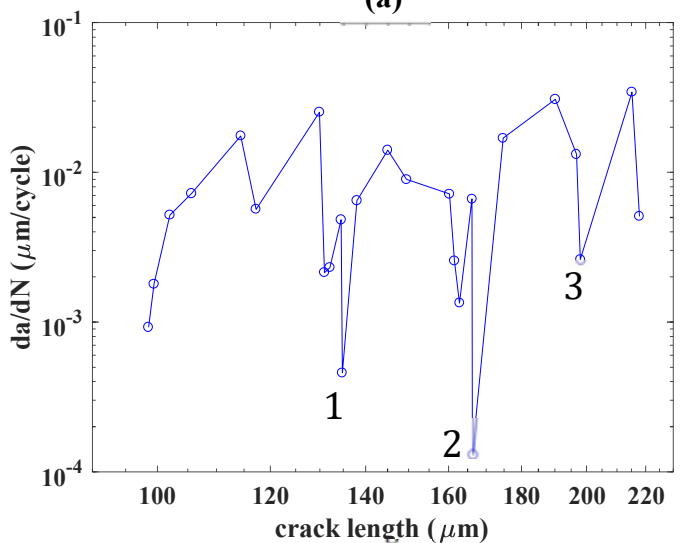

(b)

Fig. 6. (a) Short crack growth ' $a$ ' with numbers of cycles ' $N$ ' and (b) short crack growth rate ' $d a / d N$ ' with crack length ' $a$ ' at applied $\Delta \sigma=475 \mathrm{MPa}$ in SA508 Gr.3 Cl.I LAS (the crack is propagated to approximately $150 \mu \mathrm{m}$ length) 

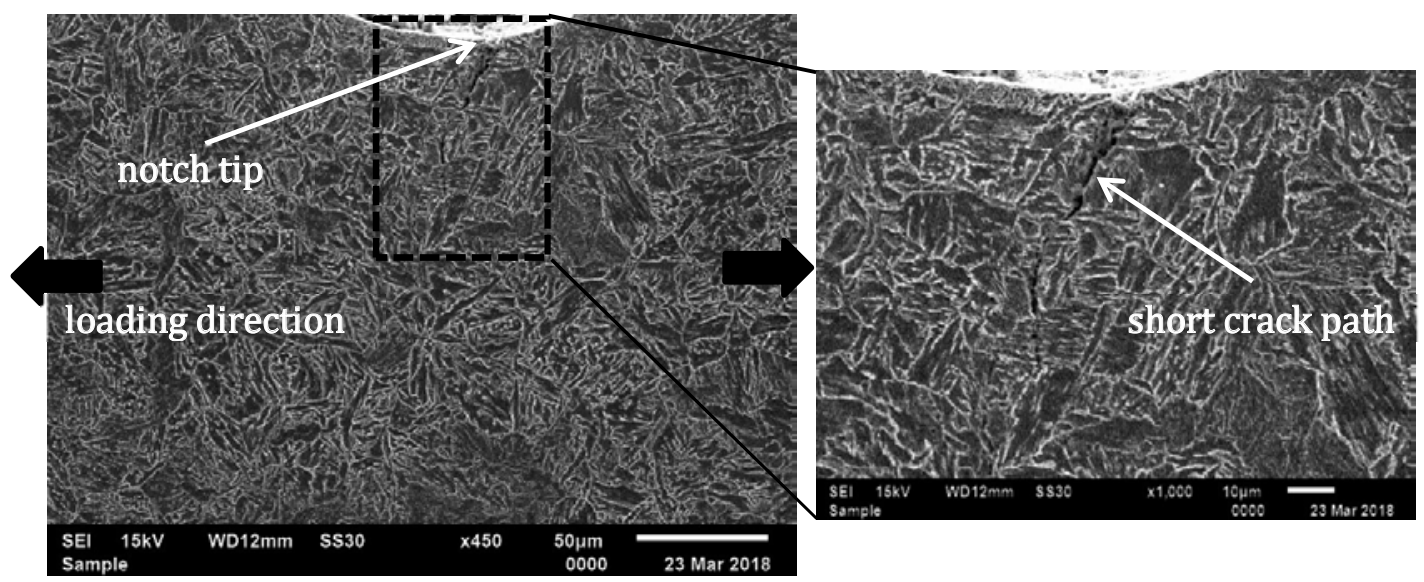

(a)

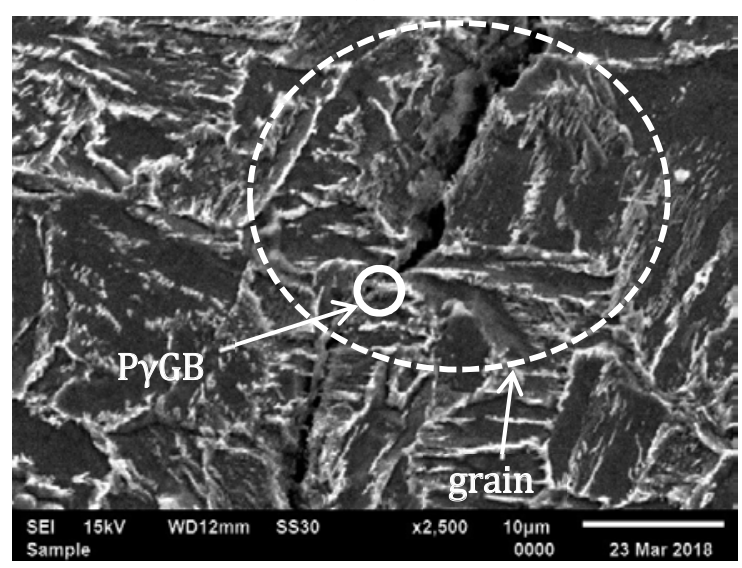

(b)

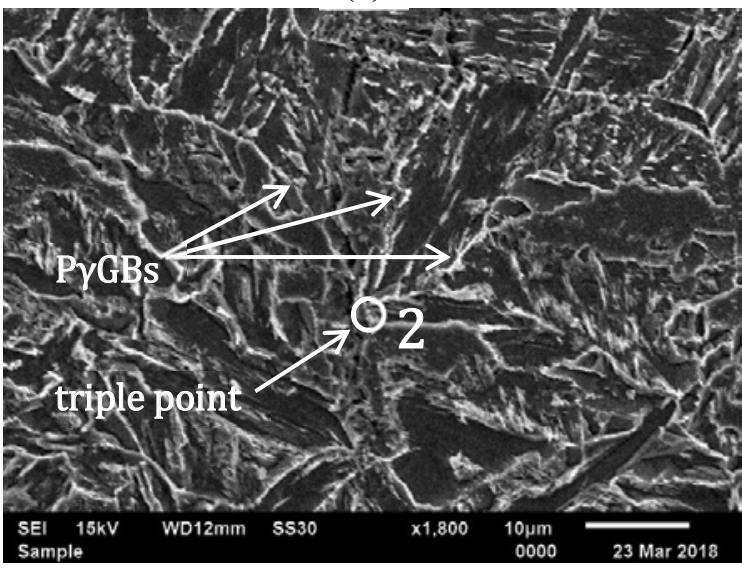

(d)

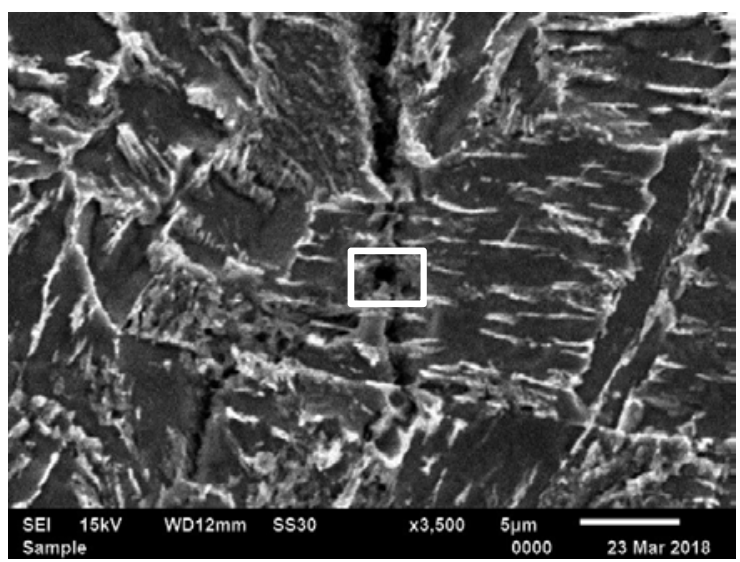

(c)

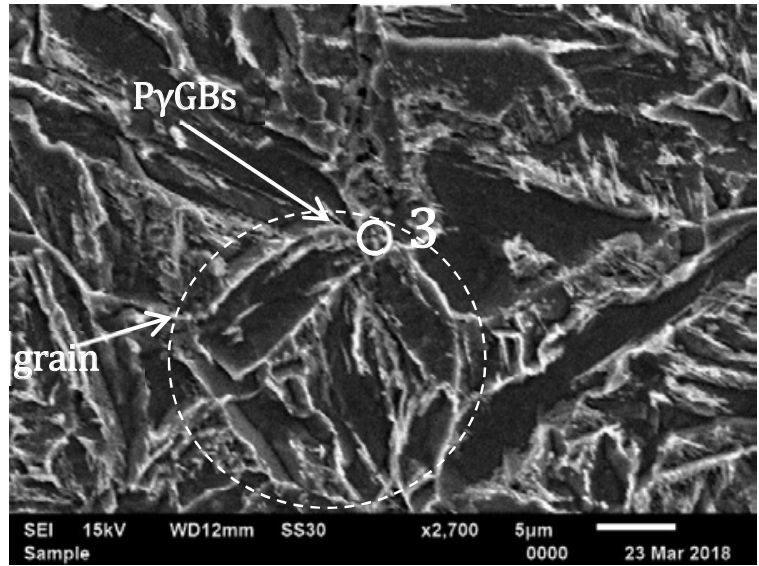

(e)

Fig. 7. Interaction of Short crack during propagation under cyclic loading with the microstructural features of SA508 Gr.3 Cl.I LAS as observed through SEM

The details regarding the interaction of short crack propagation with the microstructural features in SA508 Gr.3 Cl.I LAS through EBSD and EDS will be presented during the $12^{\text {th }}$ international fatigue congress and a fulllength paper of the detailed work will be submitted in a reputed journal.

\section{Conclusion}

The following conclusions are drawn from the comparative study of short and long crack propagation under cyclic loading in SA508 Gr.3 Cl.I LAS:

1. The short crack propagation rate at higher stress levels i.e. above the yield strength of the material cannot be predicted by the Paris-Erdogan law. Therefore, the design 
of pressure vessels installed in nuclear power plants merely on long crack growth data is not recommended.

2. The short crack propagation rate is highly influenced by the P $\gamma$ GBs in SA508 Gr.3 Cl.I LAS.

3. The triple point in the material acted as a source for the initiation of the short cracks under cyclic loading.

References

1. K. J. Miller, Fatigue of engineering materials and structures 5, 223 (1982).

2. A. J. McEvily, Transactions on Engineering Sciences 13, 93 (1996).

3. C. Bjerken and S. Melin, International Journal of Solids and Structures 46, 1196 (2009).

4. J. C. Newman, E. P. Phillips, and M. H. Swain, International journal of fatigue 21, 109 (1999).

5. R. Strubbia, S. Hereñú, L. Alvarez-Armas, and U. Krupp, Materials Science \& Engineering A 615, 169 (2014).

6. C. Kaynak, A. Ankara, and T. J. Baker, International journal of fatigue 18, 17 (1996).

7. M. Kim, S. Park, K. Lee, and B. Lee, International Journal of Pressure Vessels and Piping 131, 60 (2015).

8. W. A. Logsdon and P. K. Liaw, Engineering Fracture Mechanics 22, 509 (1985).

9. J. Y. Huang, J. J. Yeh, R. C. Kuo, S. L. Jeng, and M. C. Young, International Journal of Pressure Vessels and Piping 85, 772 (2008).

10. S. G. Lee and I. S. Kim, Journal of pressure vessel technology 123, 173 (2001).

11. I. S. Kim and S. S. Kang, International Journal of Pressure Vessels and Piping 62, 123 (1995).

12. L. Dong, Q. Peng, E. Han, W. Ke, and L. Wang, Journal of Materials Science \& Technology (2017).

13. J.-T. Kim, B.-I. Yang, and H.-K. Kwon, ASME 2002 Pressure Vessels and Piping Conference, 181.

14. J. L. Breat, F. Mudry, and A. Pineau, Fatigue of engineering materials and structures 6, 349 (1983).

15. R. Singh, A. Singh, P. K. Singh, and D. K. Mahajan, International journal of fatigue (under review).

16. R. I. Stephens, A. Fatemi, R. R. Stephens, and H. O. Fuchs, John Wiley \& Sons, Inc. 2nd edition (2001).

17. R. D. Brown and J. Weertman, Engineering Fracture Mechanics 10, 757 (1978).

18. A. Manonukul and F. P. E. Dunne, Proceedings of the Royal Society A: Mathematical, Physical and Engineering Sciences 460, 1881 (2004). 